Research Journal of Applied Sciences, Engineering and Technology 7(2): 424-429, 2014

DOI:10.19026/rjaset.7.271

ISSN: 2040-7459; e-ISSN: 2040-7467

(C) 2014 Maxwell Scientific Publication Corp.

\begin{tabular}{lll}
\hline Submitted: July 1, 2013 & Accepted: July 17, 2013 & Published: January 10, 2014
\end{tabular}

Research Article

\title{
Sustainable Development through Energy Management: Issues and Priorities in Energy Savings
}

\author{
${ }^{1}$ Usama Awan, ${ }^{2}$ Naveed Imran and ${ }^{3}$ Gulnaz Munir \\ ${ }^{1}$ COMSATS Institute of Information Technology, Vehari, Pakistan \\ ${ }^{2}$ Quaid-i-Azam University, Islamabad, Pakistan \\ ${ }^{3}$ Bahauddin Zakariya University, Multan, Pakistan
}

\begin{abstract}
This study aims to study and summarized the some best practices and initiative of corporations towards energy management and its role and contribution to sustainable development. This study also intends to highlight the deficiencies in formulating the energy policies and setting goals in order to improve the living standards of humans and contribution into sustainable development Energy management is one of the contemporary challenge, this study adopts an exploratory approach purely based on existing literature review on energy management, efficiency and best cost reduction methods adopted by organizations and this clearly demonstrate the need to follows a systematical approach to achieve sustainable development. Findings of this study point out that planning for energy management and its utilization is as important as energy is essential for development of sustainable factor like social, economic and environment. Developing smart approach is inevitable to meet the demand of future generations. Achieving noteworthy energy efficiency by management practices makes practical business strategy for any organization and sustainable development is basis on four pillars social, economic, environment and energy sources management.
\end{abstract}

Keywords: Efficiency, energy, energy management, renewable energy, sustainable development

\section{INTRODUCTION}

In order to explain and find out the indicators for sustainable developments the important is energy considered a key factor in discussion of economic, social and environmental spheres in sustainable development (Dincer, 1999). Sustainable development requires a better fit between among all the stakeholders 'not necessarily less government, a sharing of tasks between state, civil society and the business sector and a long term perspectives addressing the population as responsible citizens' (Meadowcroft, 2007).

Therefore, the important issue is to address the demand of the energy supply and develop energy management strategies for sustainable future. The sustainable supply of green energy is generally considered to a fundamental element in the establishing the relationship between the social and environment development; this concept is associated with sources of renewable which are finite in nature for society and sustainable over relatively long term (Dincer and Rosen, 2004).

The most important challenges among other is ensuring energy for sustainable development (improving human, economic, social and environmental) issues and Energy is corner stone of today modern life.
Demand of energy is growing continuously and essential for developing countries for their society, economic and social improvements and this requires deliver more affordable services, changes in technologies, methods, infrastructure and people behavior (Kaygusuz, 2012). The energy efficiency are give high priority in developed countries as compared with the less developed countries, living human species of this planet taking into consideration of environmental issues.

Sustainable development creates conditions for developing a system which can be pursued effectively and can be mutually reinforce (Hennicke et al., 2007). Developing countries have different usage patterns of energy savings and efficiency and do not have to follow the example of developed countries. Since last 20 years the sustainable development problem has become even more a challenging and at the same time providing opportunities and new pillars for development of future generations. The process of scenario analysis involves, a process of natural learning and production of mutual knowledge is important for shorten the gap of global challenging and widening the opportunities for different stakeholders (Swarta et al., 2004). "Sustainable development is probably the most demanding policy concept ever developed and promoted. This implies a need for new mechanisms and it encompasses all domains of policies and it requires nothing less than a

Corresponding Author: Usama Awan, COMSATS Institute of Information Technology, Vehari, Pakistan

This work is licensed under a Creative Commons Attribution 4.0 International License (URL: http://creativecommons.org/licenses/by/4.0/). 
revolution in thinking, a new view on old problems and approaches". The aim of sustainable development is to improve the living standards of society and enable them to act for the betterment of their society and protecting the social and environmental issues on priority (Meadows et al., 1992). Sustainable development includes social, economical, technological and environmental issues that provide opportunities to countries for a better future (OECD Environment Directorate, 2004). According to the World Commission on Environment and Developments (1987) define term sustainable as "meeting the needs of the present generation with compromising the ability of future generations to meet their own needs" and term development as "involves a progressive transformation of economy and society".

Form the study of the literature it is noted that many studies have been carried out to better understand the implementation of the sustainable development aspects in energy sources and applications (Wustenhagen and Bilharz, 2006; Dincer and Rosen, 2004; Halasz et al., 2005; Hughes and Johnston, 2005). The primary focus of this paper is to study and motivation behind it to develop some important energy efficiency measures and key parameters through like energy saving practices that leads to the sustainable future for the future generations. However the objective of this study is to give an idea to manage the energy sources and reduce the negative environmental impacts and provides the new strategic vision how to use and conservation of the energy sources efficiently and providing methods for development of energy sources.

\section{ENERGY EFFICIENCY}

Earth Summit in 1992 recognized the need for development indicators can play important role particular for developing countries to make informed decisions concerning sustainable development. In continuation to this approach a number of governmental and non-governmental agencies started working on development of indicators and statistics tools to measure the energy management techniques and usage patterns for a deeper understanding of causal relationships and linkages exits in the social, energy and environmental development (Vera and Langlois, 2007).

Corporate energy crisis management is a set of those practices and corporation among those units of organizations involved in information gathering and decision making on energy uses and systematically supply control (Dincer, 1999). Practices of saving energy and information flow in organizations include everything from setting energy saving missions and objective for each department and to assigning the task for effectively management of policies and monitor the employees to tracking energy uses practices and to identify the opportunities to minimize use of energy and participate in planning new energy operating practices

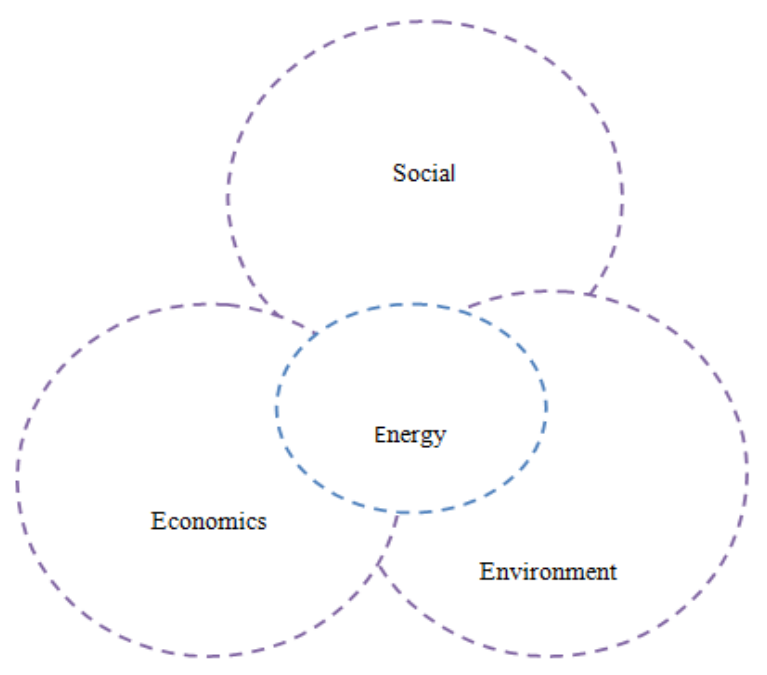

Fig. 1: Determinant of sustainable development

and got recognizing employee with achievements awards (Demirbas et al., 1998). According to Demirbas (1998) majority of people are paying bills more than they should charge for their needs. Its important to understand the needs of saving energy when all of your utility bills are growing (Demirbas, 2000) is in the view that most of the people are on gas or electricity suppliers provides standardized plan, means that most consumers are paying the highest utility prices.

The model Determinant of Sustainable Development (Fig. 1) can be very helpful for explaining why the energy is central part of the sustainable development. This model also distinguishes and determinant the importance of the energy efficiency management is an upmost need for the future generations. Therefore, the energy efficiency programs have to give special focus along with other all three determinant of sustainable development. This fourth phase of sustainable development can have dramatic benefits for the rural and urban families. Energy development and its efficient management have had profound impact on the environment, economic and social development. Energy management has always been critical issue as both driving force for sustainable development. Energy management is even more critical issue as demands of the energy are increasing day by day. As energy is needed not for only the development of the economy but it is also more needed for household and business uses, such as for lighting, cooking, agriculture, communication, water supply, education, health and transportation.

Energy management practices: Electricity and energy resources are not only value added commodities, these are blessings that deliver comfort and escalate living standards (Edinger and Kaul, 2000). Adequately smart management and controls lead to significant savings as direct benefits and sustainability on long term. The balance and controls of nature always have stronger 
reactions that sustain. The mankind has been pushed to this corner of natural reaction or our sustainability shall be at stake (Flavin and Dunn, 1998). The others understand when international standards are developed and entrepreneurs start implementing those standards (Haydel et al., 1997) particularly focusing study with a holistic approach to determine guidelines that would facilitate managing energy crisis (Peach et al., 1997).

\section{ENERGY VALIDATED APPROACHES}

Dincer and Rosen (2005) broad-based research found that energy and resources sustainability, economic sustainability, environmental sustainability and social sustainability are essential factors impacting on achieving the sustainable development Can only be met through the deployment and use of energy efficient modern technologies (Kaygusuz, 1999) requires energy research and development to take into the account of their contribution towards reducing the environmental impact (OECD Environment Directorate, 2004) is considered to have strong intensity in development of growth make strategy and to develop more energy efficient technologies ( $\mathrm{Ng}$ and Nathwani, 2011).

Current study is facilitation for those who are following track to survive and are exposed to elevated temperatures of energy crisis due to wastage malpractices. Smart organizations have studied their systems, implemented better management practices and reported guidelines (Kagazyo et al., 1997). Kaygusuz (1999) argued that the points are listed below as worked best for informed companies.

The elements are characterized as:

- Involvement of CEO office

- Defined energy saving missions and goals

- Communicate goals to all the employees

- Assignment of responsibility and accountability

- Tracking and implementation of energy uses

- Continues monitoring of potential projects

- Adoption and identification of project investment, risks and returns.

- Recognition and provision of reward

According to Midilli et al. (2005) Employees as team members have a generic response of a tuned channel. Whatever top management will tune only that channel is played. Over $70 \%$ of companies have reported serious top management commitment in various surveys towards energy management goal. Eighty five percent of these companies were required periodic progress reporting, as well as communicating its importance throughout the corporation. Sixty percent of cases had endorsed the goal and signed a policy which put focus on corporate energy management. Almost more than $33 \%$ of the companies signed the policy recognizing the achievement of their employees implementing the corporate mission and attaining the goals. Companies focused on energy management ranked the following in order of most least important as:

- Focus on energy supplies that reduce cost

- Invest in effective energy resource management

- Procure quality energy supplies

- Embrace environmental stewardship in energy uses

- Use of Environmental friendly technology

- Treat energy department in the same way as other departments

These practices establish a link with the structure of ISO 9001-2008 Quality Management System International Standard. The finding unfolds a similar result as accepted reality behind establishment of the Quality Management System Standard. These allowing companies to face intense competition in asset intensive, business cyclical, which is constantly battling erosion of product value with gains in productivity (Momirlan and Veziroglu, 2002).

However, energy efficiency is the most effective measure in addressing the challenge of energy management and reduction of emission of green house gases. Gardner and Stern (2002) makes clear distinction between the energy efficiency and energy conservations, energy efficiency refers to the adoption of specific technology that reduces the consumption of energy without changing the relevant behavior and energy conservations refers to changing consumer behavior towards energy savings. There are a number of barriers in energy efficiency, the most important barriers included, lack of technical and financial support, access to renewable technologies, lack of information about energy efficient technologies and knowledge at producer and consumer level and lack of adequacy in implementation of policies (Chandler and Gwin, 2008). Furthermore, the study of Harald et al. (2008) Shows that the strength of Information barrier as consumers need relevant information what practices are available and how to save energy. Despite this, lack of information available for consumers is considered one of the barriers for adoption of energy efficient technologies. The best way to overcome this barrier is to provide information to consumers about energy efficiency and encouraging to compare products and choose the most energy efficient product (Maria et al., 2007; Amuzuvi and Attachie, 2013).

Crossley (1983) recognize six potential barriers from macro-to micro-oriented and ranked as:

- Personal predisposition

- Living situation

- Economic costs

- Social costs 
- Inadequate information

- Barriers arising out of structural factors

Tester et al. (1991) suggest that looking ideally on the ultimate effort is to achieve impossible target of zero waste in manufacturing. The focus on minimizing waste in production as another form of countable and controllable waste. The approach has been three pronged:

- Purchasing of energy efficiency supplies

- Creative assessment of suppliers

- Enhancement of energy efficiency

Strategic track has emerged to define "Corporate Energy Policy with the objective to improve energy consumption efficiency, reduce cost, decrease capital investment, reduce environmental emissions and conserve natural resources" (UNDP, 2000). The importance of a common individual and shop floor employees cannot be ignored and organizations have taken their people affectively on board, disseminated knowledge, innovatively educated. The facilitation has not only served saving energy in the workplace but at their home as well. This is provoking a high sensational level of concern in the people and not leaving any achievement on chance within domain of energy crisis management system. Systematic achievement involves assignment of responsibility and accountability in all type of setups. In doing this, it is also pertinent to form task force rather depending on the authority in one person. For example, in some organization while implementing the best practices measures are not forced on facility managers, but to receive credit toward the company's energy reduction target, they need to implement all of them that pass the company's costeffectiveness test (Massoud, 2008).

Facilitation in accountability comes with methods of tracking energy use metrics. It is stated that "If you do not measure it, you cannot control it is an old adage that applies fully to energy efficiency". This method is help as advancing management approach in energy efficiency goals to best track of energy use and curtailed the cost as possible as possible reporting cost and time. Energy use data upon metering at appropriate levels would further be compared with utility meters and bills. The energy track makes process and nonprocess uses energy efficient (Haydel et al., 1997). This management approach provoke the idea of measurement of output in production process, it is associated with the value of product and intermediate processes. For other process facilities use of energy may be compared to square footage number of employees or hours of operation. This approach has further developed giving importance of energy to air and carbon emissions. Consolidated formation of energy metrics keeps the systems on toes and is vital.
Implementing energy metrics based reporting system makes a setup reasonably fertile for further development as continuous improvement.

Kauffman (1999) has shown the continuous improvement involves challenging all processes, equipment, activities and work flows like:

- Does the equipment operate the way it should operate?

- Can the process variables be optimized?

- Does the equipment operate only when necessary?

- Is time and motion in efficient harmony?

Typically firms do not have sufficient capital and necessary fund for all energy crises proactive management approaches and right away control all processes and projects. Thus, continuous identification and establishing projects related to energy efficiency to achieve goals of corporation and smoothly operating and utilization of resources optimally. The process of development in energy management practices unfolds further opportunities of New Projects Selection Criteria Reflecting Risk and Returns for energy concerned organizations identify that energy savings initiatives often generate more revenue at low risk rate with an average $300 \%$ return on investment. The companies involve in achieving energy efficiency goals requires overall cost of capital as financial criteria for energy efficiency investment (Peach et al., 1997).

These achievements are great and worth Recognition and Rewards for performers who achieve Energy Goals. Although rewards are not a weapon of increasing motivation but recognizing the effort of persons. Most of organizations adopted this policy to give away the rewards for achieving significant reductions in cost of energy. Some have learned that a little recognition goes a long way to obtaining superior performance (Norland and Lind, 2000).

\section{CONCLUSION}

For addressing successfully these challenges corporations needs to tailored each employee and start initiative related to energy supply that can reduce the cost of energy. The corporations should look and take into account their internal resources as challenged to keep up their goals. The firms should put more focus on procurement of energy supplies, monitoring the energy risk associated with changing in economic conditions, implementing energy supplies strategies, get benefit from maximizing supplier competition in procurement of energy.

Corporations can increase their companies through forming task forces and committees to develop rules and related framework for transfer of energy technologies would be an added benefit in bringing output in energy management. The practices include 
energy monitoring and measurement, setting standards on per unit usage basis and assign responsibilities, take people on board through affective communication within domain of the corporation and above all recognize efforts of staff who strive and achieve energy objectives. This loop could be close circled by including Corporate Energy Conscious Policy in pedagogical manner with the objective to improve energy consumption efficiency as a never ending story.

The priorities of organizations led them to formally implement the policies of best energy practices and cost reduction. The best thing is to formulate policies, creating awareness about energy saving goals rather than producing the information.

The itemized elements as model best practices should be packaged and promoted as a national program of promotion, motivation and reward for energy crisis management best practices on the part of all entrepreneurs. Achieving noteworthy energy reduction by management practices makes logical business strategy for any organization and sustainable development is basis on four pillars social, economic, environment and energy sources management. Three phases of development are social, economic and development and these developments sustains on the energy development.

Managerial applications: Managers should develop indicators for measuring employee's habits of saving energy and link it is link with the performance awards and companies should define responsibility in their current role of all head of department's in-terms of saving energy. Adopting this insight would help lowering the scale of utility bills in today volatile and complexity of energy market.

\section{ACKNOWLEDGMENT}

The authors are very grateful to the anonymous referees for the insightful comments and suggestions.

\section{REFERENCES}

Amuzuvi, C.K. and J.C. Attachie, 2013. Effective power management in homes and premises in Ghana. Res. J. Appl. Sci. Eng. Technol., 6(3): 354-360.

Chandler, W. and H. Gwin, 2008. Financing Energy Efficiency in China. Carnegie Endowment for International Peace, Washington, D.C., pp: 11-17.

Crossley, D.J., 1983. Identifying barriers to the success of consumer energy conservation policies. Energy, 8(7): 533-546.

Demirbas, A., 1998. Energy education: Energy concepts and risks of alternative energy resources in Turkey. Energ. Educ. Sci. Technol., 2: 29-42.
Demirbas, A., 2000. Biomass resources for energy and chemical industry. Energ. Educ. Sci. Technol., 5: 21-45.

Demirbas, A., F. Dumanoglu and A. Ayas, 1998. Energy concepts and energy education in chemistry. Energy Educ. Sci. Technol., 1: 17-23.

Dincer, I., 1999. Environmental impacts of energy. Energ. Policy, 27: 845-854.

Dincer, I. and M.A. Rosen, 2004. Exergy as a driver for achieving sustainability. Int. J. Green Energ., 1(1): $1-19$.

Dincer, I. and M.A. Rosen, 2005. Hermodynamic aspects of renewable and sustainable development. Renew. Sust. Energ. Rev., 9: 169-189.

Edinger, R. and S. Kaul, 2000. Humankind's detour toward sustainability: Past, present and future of renewable energies and electric power generation. Sustain. Energ. Rev., 4: 295-313.

Flavin, C. and S. Dunn, 1998. Climate of opportunity: Renewable energy after Kyoto. Renew. Energy Policy Project. Retrieved from: http:// www. repp.org/ repp_pubs/ pdf/ ssuebr11. pdf. (Accessed on: May 08, 2013).

Gardner, G.T. and P.C. Stern, 2002. Environmental Problems and Human Behavior. 2nd Edn., Pearson, Boston, MA.

Halasz, L., G. Povoden and M. Narodoslawsky, 2005. Sustainable processes synthesis for renewable resources. Resour. Conserv. Recycl., 44: 293-307.

Harald, T.H., S. Pål and S. Eivind, 2008. Identification of households' barriers to energy saving solution, management of environmental quality. Int. J., 19(1): 54-66.

Haydel, J., W. Steven and H.M. Pamela, 1997. Tracking Energy Use at Industrial Companies. How Industry Will Procure Energy Efficiency Services in the 21st Century. ACEEE Summer Study on Energy Efficiency Services in Industry. Sheraton Saratoga Sprins Saratoga Springs, NY., June 8-11, pp: 5-6.

Hennicke, P., S. Borbonus and C. Woerlen, 2007. The GEF's interventions in the climate change focal area: the contribution to strategies for climate change mitigation and sustainable development. Energ. Sustain. Dev., 11(1): 13-25.

Hughes, B.B. and P.D. Johnston, 2005. Sustainable futures: Policies for global development. Future, 37(8): 813-831.

Kagazyo, T., K. Kaneko, M. Akai and K. Hij, 1997. Methodology and evaluation of priorities for energy and environmental research projects. Energy 22: 121-129.

Kauffman, H.A., 1999. Johnson and Johnson Strives to Implement Best Practices by Year 2000. Industry and Innovation in the 21st Century: 1999 ACEEE Summer Study on Energy Efficiency in Industry. Sheraton Saratoga Springs Saratoga Springs, NY, June 15-18, pp: 3-5. 
Kaygusuz, K., 1999. Energy situation, future developments, energy saving and energy efficiency in Turkey. Energ. Source, 21: 405-416.

Kaygusuz, K., 2012. Energy for sustainable development: A case of developing countries. Renew. Sust. Energ. Rev., 16: 1116-1126.

Maria, P., M. Ornella and S. Stefania, 2007. Eco-labels: A sustainability performance in benchmarking? Manag. Environ. Qual. Int. J., 18(16): 669-683.

Massoud, A., 2008. The electric price of politics. The Herald, pp: 83-84.

Meadowcroft, J., 2007. National sustainable development strategies: features, challenges and refl exivity. Eur. Environ., 17(3): 147-151.

Meadows, D.H., D.L. Meadows and J. Randers, 1992. Beyond the Limits: Confronting Global Colllapse, Envisioning a Sustainable Future. Chelsea Green Publishing Co., London.

Midilli, A., M. Ay, I. Dincer and M.A. Rosen, 2005. On hydrogen and hydrogen energy strategies I: Current status and needs. Renew. Sust. Energ. Rev., 9: 255-271.

Momirlan, M. and T. Veziroglu, 2002. Current status of hydrogen energy. Renew. Sust. Energ. Rev., 6: 141-179.

$\mathrm{Ng}$, W.A. and J. Nathwani, 2011. Strategic development and growth of emerging renewable energy ventures from China: Real options through mergers and acquisitions. J. Technol. Manage. China, 6(2): 116-124.

Norland, D.L. and L. Lind, 2000. Energy management: A survey of large manufacture companies. Proceedings of the 22nd National Industrial Energy Technology Conference. Houston, Taxas, USA.
OECD Environment Directorate, 2004. State of the Environment Division, Using the Pressure-StateResponse Model to Develop Indicators of Sustainability. OECD Framework for Environmental Indicators. Retrieved from: destinet.eu/ ...indicator_model.../ OECD_P-S$\mathrm{R}$ indicator model.pdf -.

Peach, H., C. Gil, B. Eric and C.G. Joseph, 1997. What works for energy efficiency in large industry. 1997 ACEEE Summer Study on Energy Efficiency in Industry.

Swarta, R.J., P. Raskinb and J. Robinson, 2004. The problem of the future: sustainability science and scenario analysis. Glob. Environ. Change, 14: 137-146.

Tester, J.W., O.D. Wood and N.A. Ferrari, 1991. Energy and the Environment in the 21st Century. Massachusetts Institute of Technology (MIT) Press, Cambridge, MA.

UNDP, 2000. United Nations Development Program (UNDP). In: Goldemberg, J. (Ed.), World Energy Assessment. Energy and the Challenge of Sustainability. UNDP/UN-DESA/World Energy Council, New York.

Vera, I. and L. Langlois, 2007. Energy indicators for sustainable development. Energy, 32: 875-882.

World Commission on Environment and Developments, 1987. Report Our Common Future. Oxford University Press, London.

Wustenhagen, R. and M. Bilharz, 2006. Green energy market development in Germany: Effective public policy and emerging customer demand. Energ. Policy, 34(13): 1681-1696. 